\title{
An Investigation of the Duration of Load of Structural Timber and the Clear Wood
}

\author{
Qiongyao $\mathrm{Wu}^{1,2}$, Liangliang Huo ${ }^{2}$, Enchun $\mathrm{Zhu}^{3, *}$, Shuang $\mathrm{Niu}^{3}$ and Huajie Wang ${ }^{3}$ \\ 1 China Construction First Group Construction \& Development Co., Ltd., Beijing 100102, China; \\ hit_wqy@163.com \\ 2 Key Laboratory of Structures Dynamic Behavior and Control of China Ministry of Education, School of Civil \\ Engineering, Harbin Institute of Technology, Harbin 150090, China; 1123310614@hit.edu.cn \\ 3 Department of Civil Engineering, Harbin Institute of Technology at Weihai, School of Ocean Engineering, \\ Weihai 264209, China; nius@hit.edu.cn (S.N.); huajie_wang@hit.edu.cn (H.W.) \\ * Correspondence: e.c.zhu@hit.edu.cn
}

Citation: Wu, Q.; Huo, L.; Zhu, E.; Niu, S.; Wang, H. An Investigation of the Duration of Load of Structural Timber and the Clear Wood. Forests 2021, 12, 1148. https://doi.org/ $10.3390 /$ f12091148

Academic Editor: Barbara Ozarska

Received: 21 July 2021

Accepted: 23 August 2021

Published: 25 August 2021

Publisher's Note: MDPI stays neutral with regard to jurisdictional claims in published maps and institutional affiliations.

Copyright: (c) 2021 by the authors. Licensee MDPI, Basel, Switzerland. This article is an open access article distributed under the terms and conditions of the Creative Commons Attribution (CC BY) license (https:// creativecommons.org/licenses/by/ $4.0 /)$.

\begin{abstract}
In this study, DOL of structural timber and the clear wood and DOL of modulus of elasticity of wood were investigated. The dimension lumber of Spruce-Pine-Fir of Grade No. 2 and Grade No. 3 and the small clear specimens of the same species of the dimension lumber were used to conduct the short-term and the long-term bending test. The short-term strength distributions of the dimension lumber and the small clear specimens were obtained. The long-term tests were conducted under constant environmental conditions for 18 months. The sample matching technique was used to estimate the short-term strength of the specimens that underwent long-term tests. It was found out that there is virtually no difference in DOL between different grades or quality of lumber and no difference between structural timber and clear wood, and DOL obtained from the test of this study is more in agreement with Wood's curve. A threshold stress ratio of about 0.55 , loaded above which the wood began to experience strength loss, was revealed from the test. Making use of the threshold ratio concept, the DOL of wood can be obtained not only from failed specimens under load in the process of the long-term loading, but also from the ramp loading test of the specimens that survived the long-term test. Sustained load also poses DOL on the modulus of elasticity of wood, though to less degree than DOL of strength of wood.
\end{abstract}

Keywords: timber; duration of load; long-term strength; Madison Curve; threshold stress ratio

\section{Introduction}

Forest resources provide wood products for building constructions, and the material properties of wood attract wide attention. Duration of load (DOL) of wood refers to the fact that the strength of wood decreases under sustained load, which is usually reflected by the ratio of the time-dependent long-term strength of wood to the short-term strength. The earliest study on DOL was conducted by Buffon [1]. He concluded that the longterm load-carrying capability of Oak beams should be less than half of the short-term capability. In 1881, Thurston [2] found out that specimens of wood in bending loaded at a stress ratio of 0.6 , the ratio of the applied stress to the short-term bending strength, also known as modulus of rupture, would fail in 8 to 15 months. In 1947, Wood [3] conducted experimental investigations of DOL of wood in bending with Douglas-fir small clear specimens, in which the short-term strength of a specimen that was to undergo the long-term test was estimated by the pair matching method. The specimens with moisture content (MC) of $6 \%$ and $12 \%$ were tested, respectively. The DOL was reflected by a linear relationship between the logarithmic failure time and the stress ratio as $S L=90.4-6.3 \lg \left(t_{\mathrm{f}}\right)$, where $S L$ was the stress ratio (\%), and $t_{\mathrm{f}}$ was the failure time of wood in hours. In 1951, the Madison Curve was then proposed by Wood [4], which was a combination of the results of Wood's long-term loading test, Liska's ramp loading test [5] and Elmendorf's impact 
test [6]. The relationship between the failure time and the stress ratio was approximated with a hyperbola as $S L=18.3+108.4 t_{\mathrm{f}}-0.0464$, where $S L$ was the stress ratio $(\%)$, and $t_{\mathrm{f}}$ was the failure time of wood in seconds. The Madison Curve is shown in Figure 1, with the asymptote being a stress ratio of $18.3 \%$. In obtaining the Madison Curve, a modified stress ratio of $150 \%$ under impact load lasting for $0.015 \mathrm{~s}$ was employed [7], instead of the ratio of $175 \%$ as measured by Elmendorf in the test. Since the Madison Curve came into being, the related research has always been compared with it. If the result of DOL falls below the Madison Curve, the DOL is said more server than the Madison Curve, otherwise less severe.

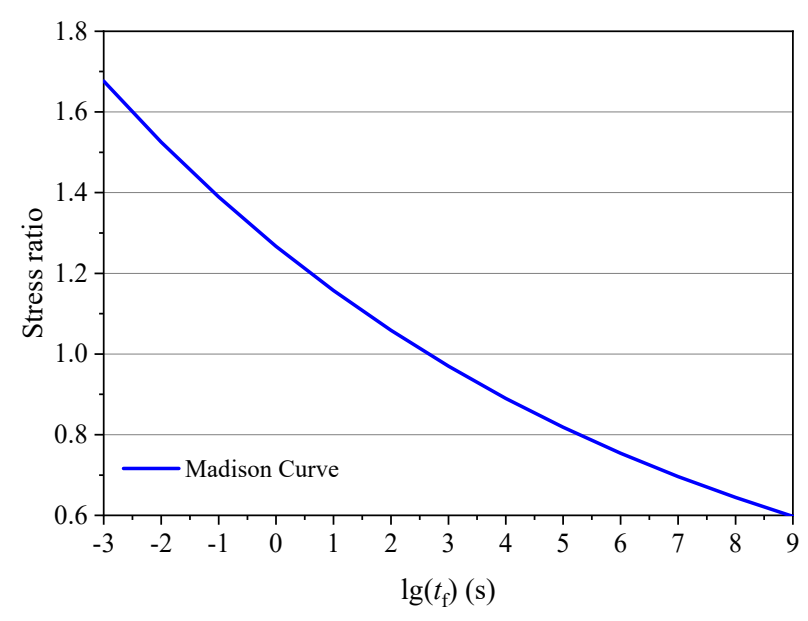

Figure 1. Madison Curve.

In the 1970s research of DOL began to focus on structural timber. Madsen and Barrett [8] investigated the DOL of Douglas-fir dimension lumber of different grades in bending. The sample matching technique [8] was used to determine the short-term strength of the dimension lumber. The environmental conditions of testing were uncontrolled indoor climate. They concluded that the DOL of dimension lumber was less severe than that identified from Madison Curve and the DOL of the higher quality lumber was more severe than the lower quality lumber.

The findings stimulated wider research interests in DOL investigations [9,10]. In 1982, Foschi and Barrett [11] explored the DOL of Hemlock dimension lumber and verified that the Madison Curve gave more severe prediction of the strength decrease than the test results. In 2000, Gerhards [12] reviewed his long-term bending test of Grade Select Structural (SS) and Grade No. 2 dimension lumber of Douglas-fir conducted in a constant temperature of $22.8^{\circ} \mathrm{C}$ and relative humidity (RH) of $50 \%$ [13]. Contrary to the results of Madsen and Barrett [8] and the results of Foschi and Barrett [11], his study indicated that DOL of the dimension lumber fell below the Madison Curve and DOL of lower quality lumber was more severe than higher quality lumber. In 2007, Hoffmeyer and Sørensen [14] presented their experimental investigations of DOL of structural timber of Norway spruce, including the effect of MC of wood on DOL. The timber was conditioned and tested at RH of $55 \%$ and $90 \%$, respectively, which gave MC of wood about $11 \%$ and $20 \%$. The investigation suggested that DOL of structural timber with MC of $11 \%$ fell between the Madison Curve and the results from Madsen and Barrett. DOL of structural timber with MC of $20 \%$ fell below the Madison Curve. The study also revealed that timber quality does not affect the DOL. Wu et al. [15] conducted experimental investigations of DOL of wood in tension perpendicular to grain with small clear specimens, the test results of DOL presented a convex curve and fell between the Madison Curve and the results from Madsen and Barrett.

So far, conclusions of DOL were all drawn from experimental studies, yet tests in the studies were not conducted under unified conditions and methods in terms of the specimens, strength estimation method (pair matching or sample matching) and the envi- 
ronment conditions (different $\mathrm{MC}$ ). There are similarities and differences in conclusions between different studies. It seems that whether the DOL of structural timber and that of clear wood is the same and whether the DOL is dependent on timber quality remain a question still worth investigating under a unified environment and methods. Furthermore, there are two opposite assumptions in dealing with the DOL of modulus of elasticity (MOE) of wood in different national design standards [16]. One assumption is that the DOL of MOE and the strength is the same, the other is that MOE has no DOL at all. The assumptions lead to a significant difference in the buckling resistance evaluations that involve MOE in design standards like Eurocode 5 [17] and NDS-2018 [18]. Explanation to this inconsistency is needed.

Given the background related above, this study aims to investigate whether there is any difference in DOL between lumber of different grades and between structural timber and the clear wood; to investigate whether there is DOL of MOE of wood. Short-term and long-term bending tests of dimension lumber of two strength grades and small clear specimens of the same species of the dimension lumber were conducted in this study. The tests were all under the same constant environmental conditions, and the same sample matching technique was used. The long-term strength and MOE over a load duration of 18 months were obtained via the tests, the DOL between different grades of lumber and that between structural timber and the clear wood was compared.

\section{Materials and Methods}

\subsection{Materials}

Canadian Spruce-Pine-Fir (Canfor, Canada) dimension lumber of Grades No. 2 and No. 3 and the cross-sectional dimension of $2^{\prime \prime} \times 6^{\prime \prime}(38 \mathrm{~mm} \times 140 \mathrm{~mm})$ was used to make specimens for the bending test, of which the strength and quality of Grade No. 2 are higher than No. 3 [18]. The dimension lumber came from same batch of standard factory products. The full-sized specimens were of original dimension lumber with a length of $2820 \mathrm{~mm}$ and the small clear specimens of size $20 \mathrm{~mm} \times 20 \mathrm{~mm} \times 410 \mathrm{~mm}$ were randomly taken from the dimension lumber. 320 full-sized specimens for each grade and 320 small clear specimens were thus prepared to investigate the DOL of dimension lumber of different quality and DOL of the clear wood. The test schemes are listed in Table 1. All specimens were conditioned under a temperature of $20 \pm 2{ }^{\circ} \mathrm{C}$ and $\mathrm{RH}$ of $65 \pm 3 \%$ before testing.

Table 1. The test schemes.

\begin{tabular}{ccccc}
\hline Specimen & Short-Term Test & Strength Distribution Verification & Long-Term Test & Total \\
\hline No. 2 & 80 & 120 & 120 & 320 \\
No. 3 & 80 & 120 & 120 & 320 \\
Small clear & 80 & 120 & 120 & 320 \\
\hline
\end{tabular}

\subsection{Sample Matching Technique}

In evaluating the DOL, the short-term strength and the long-term strength of the same specimen are needed. However, a specimen could not be broken twice. The precondition for evaluating DOL is to estimate correctly the short-term strength of a specimen that is to undergo long-term testing. Different methods to estimate the strength of specimen had been tried. Pair matching was once used to evaluate the short-term strength of small clear specimens [3]. In this method, three adjacent specimens are simultaneously cut from the timber. Assuming that the strength of the middle specimen is equal to the average strength of the two specimens on the side, the two side specimens are tested for the strength, and the middle one is left for long-term test. In investigating the DOL of structural timber, pair matching was once used to evaluate the short-term strength of timber. Norén [19] attempted to use this method by sawing the structural timber with great care to obtain identical full-sized specimens, yet the accuracy of the results was poor, the method proved not feasible. Sample matching was then proposed by Madsen and Barrett [8]. In this 
method, two samples of specimens with adequate sample sizes from the same source are assumed to have the same strength distribution. Specimens of one sample are tested for short-term strength, and specimens of the other sample are to undergo long-term test. The strength of a specimen under certainly applied stress decreases with time and it may fail at a particular time. If a specimen fails, the long-term strength equals to the applied stress, and the sequence of failure indicates the strength percentile of the specimen. The short-term strength of a specimen in the long-term test is assumed to be equal to the strength of the same percentile in the short-term test. The DOL of a failed specimen under constant load is represented by the ratio of the applied stress (long-term strength) to the short-term strength of the same percentile following the sample matching technique. In this study, sample matching was used for both the structural timber and the clear wood.

\subsection{Short-Term Test}

Dimension lumber specimens all with a span of $2520 \mathrm{~mm}$ and a span to depth ratio of 18: 1 , were tested in third-point edgewise bending via a Metriguard Model 312 Bending Proof Tester (Metriguard, Pullman, WA, USA). Dimension lumber in the bending test failed in about $7.5 \mathrm{~min}$ in average (about $5 \mathrm{~mm} / \mathrm{min}$ ), being consistent with the recommendation of Standard GB/T 50329-2012 [20]. Small clear specimens all with a span of $360 \mathrm{~mm}$ and the same span to depth ratio as dimension lumber were also tested in third-point bending via a universal testing machine, with the load being parallel to the tangential direction. A specimen failed in about $1.7 \mathrm{~min}$ in average, being consistent with the recommendation of Standard GB/T 1936.1-2009 [21]. The moisture content of Grade No. 2 and No. 3 dimension lumber and small clear specimens was $12.0 \%, 11.8 \%$ and $12.2 \%$, respectively, each measured via oven-drying with 30 wood pieces of $20 \mathrm{~mm} \times 20 \mathrm{~mm} \times 20 \mathrm{~mm}$ from the respective group after testing.

Then, 2-P Weibull distribution [22] was used to fit the short-term strength. The distribution can be expressed as

$$
\sigma_{\mathrm{S}}=m(-\ln (1-p))^{1 / k}
$$

where $m$ is the scale parameter; $k$ is the shape parameter; $p$ represents the percentile of strength; $\sigma_{\mathrm{S}}$ is the short-term strength.

To verify the accuracy of the calibrated 2-P Weibull distributions, 120 specimens were taken from each respective group of the specimens, and were randomly divided into two groups of 60 specimens each to conduct the short-term tests with the same loading conditions as mentioned above.

\subsection{Long-Term Test}

Long-term test was performed in an environment of constant temperature of $20 \pm 3{ }^{\circ} \mathrm{C}$ and $\mathrm{RH}$ of $65 \pm 5 \%$. As shown in Figure $2 \mathrm{a}$, forty loading rigs similar to the design of Hoffmeyer and Sørensen's (2007) were manufactured for the bending test of dimension lumber. Load was applied to a specimen in third-point bending via a load distribution beam. A pulley with two lever arms of force, which were $60 \mathrm{~mm}$ and $300 \mathrm{~mm}$ long, respectively, was installed in the rig. A bucket containing steel emery was connected to the lever arm of $300 \mathrm{~mm}$ long and the distribution beam was connected to the lever arm of $60 \mathrm{~mm}$ long such that the force to counterbalance the weight of steel emery was magnified by a ratio of 5 . As shown in Figure $2 b$, forty test rigs were designed and manufactured for the test of the small clear specimens. Third-point bending load was applied to the specimen by a lifting jack via two springs. A stress ring was installed to monitor and control the load. 


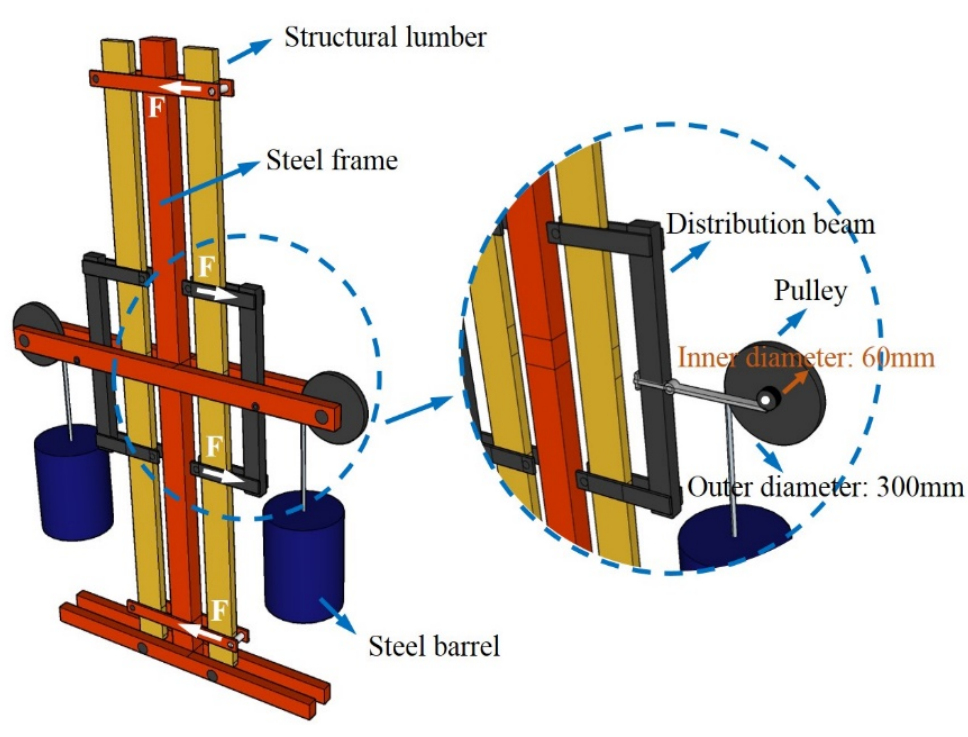

(a)

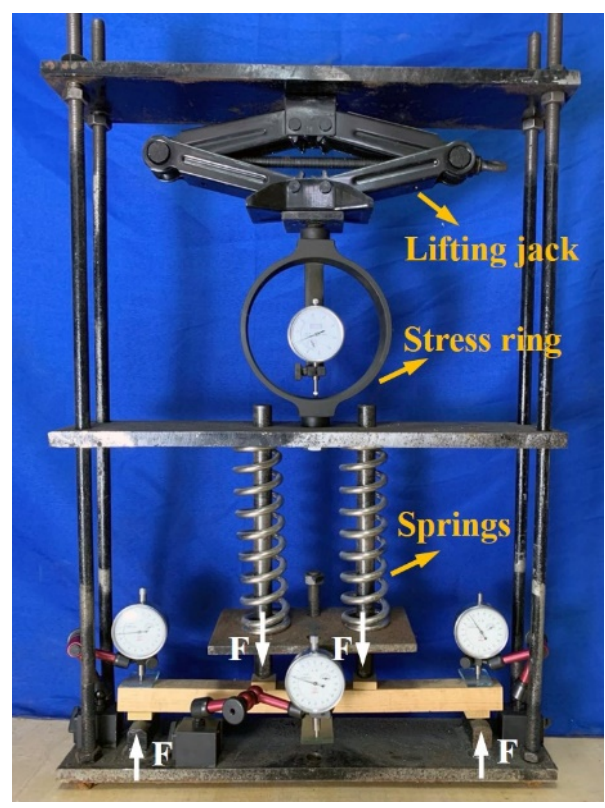

(b)

Figure 2. Long-term bending test of dimension lumber and the clear wood. (a) Dimension lumber, (b) Small clear specimen.

Specimens of Grade No. 2 dimension lumber, Grade No. 3 dimension lumber and the small clear were divided into two sub-samples, respectively, with each sub-sample consisting of 60 specimens. Stress levels equaling to the 15th percentile and 25th percentile of the short-term strength were applied to the specimens in two sub-samples of each group, respectively. A number of specimens failed in the ramp loading stage of the long-term test (BOL, broken on up-loading), some specimens failed under constant load as the test progressed, and some others survived the long-term loading. For the survived specimens, ramp loading test was conducted immediately after the long-term tests to obtain the residual strength and MOE.

The effectiveness of sample matching can be validated by the number of the BOL's. For example, for a group of 60 specimens under the stress of the 15th percentile of the short-term strength, there should be about 9 failures $(60 \times 0.15)$ in applying the target load. For a group of 60 specimens under the stress of the 25 th percentile of the short-term strength, there should be about 15 failures $(60 \times 0.25)$. These expectations of failure will be compared with test results in the Section 3.2.

Meanwhile, in the ramp loading stage of the long-term test, all specimens were installed with dial gauges to obtain the load-deflection curves. Following EN 408 [23], the section of load-deflection curve between $10 \%$ and $40 \%$ of the mean maximum load from the short-term tests was used to calculate the MOE (short-term). The MOE of the survival specimens, i.e., the long-term MOE, was also obtained via the same method.

Long-term bending test of Grade No. 2 dimension lumber and small clear specimens were conducted first, followed by the test of Grade No. 3 dimension lumber. Once a specimen failed, it was replaced immediately with a new one, making efficient use of the test rigs. In the long-term test, load on each specimen was designed to last for 18 months, taking a total test period of 40 months.

\section{Results}

\subsection{Short-Term Test Results}

The cumulative distributions of the short-term strength are shown in Figure 3, together with the calibrated 2-P Weibull distribution curves. The mean and the coefficient of variation (COV) of the short-term strength are listed in Table 2, along with the calibrated parameters of the 2-P Weibull distribution. The coefficient of determination $\left(R^{2}\right)$ between 
the strength from the test and the strength predicted by the 2-P Weibull distribution is also included in the table.

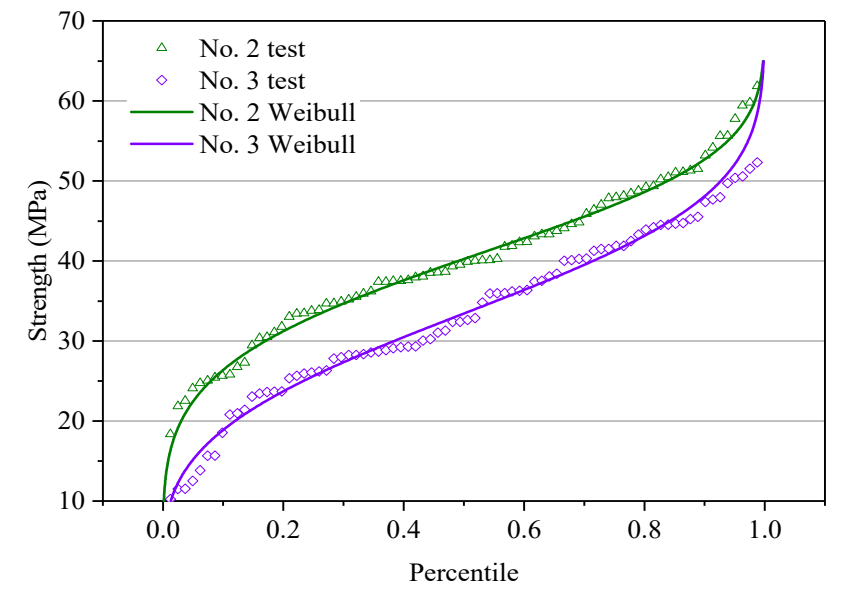

(a)

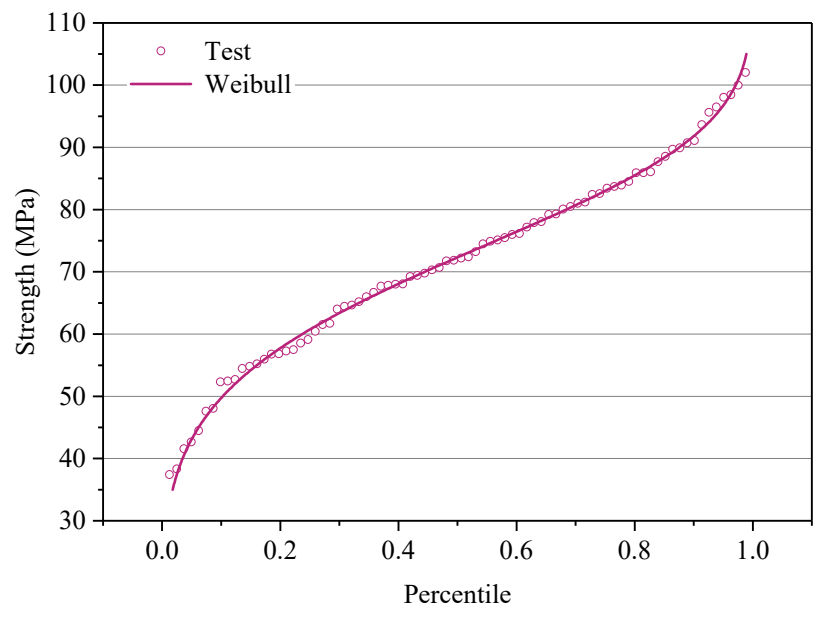

(b)

Figure 3. Short-term bending strength distributions. (a) Dimension lumber, (b) Small clear specimen.

Table 2. Parameters of the short-term bending strength.

\begin{tabular}{cccccc}
\hline \multirow{2}{*}{ Specimen } & \multirow{2}{*}{ Mean (MPa) } & \multirow{2}{*}{ COV } & \multicolumn{2}{c}{ 2-P Weibull Distribution } & \multirow{2}{*}{$\mathbf{R}^{\mathbf{2}}$} \\
\cline { 4 - 5 } & & & Scale $\boldsymbol{m}$ & Shape $\boldsymbol{k}$ & \\
\hline No. 2 & 40.15 & 0.24 & 43.702 & 4.458 & 0.992 \\
No. 3 & 33.19 & 0.32 & 37.359 & 3.299 & 0.982 \\
Small clear & 71.61 & 0.21 & 77.785 & 5.033 & 0.996 \\
\hline
\end{tabular}

The test results and the curves of the calibrated 2-P Weibull distributions are shown in Figure 4. The coefficient of determination $R^{2}$ is listed in Table 3, which indicates that the calibrated 2-P Weibull distribution models represent the short-term strength distributions very well. The accuracy of sample matching is thus validated.

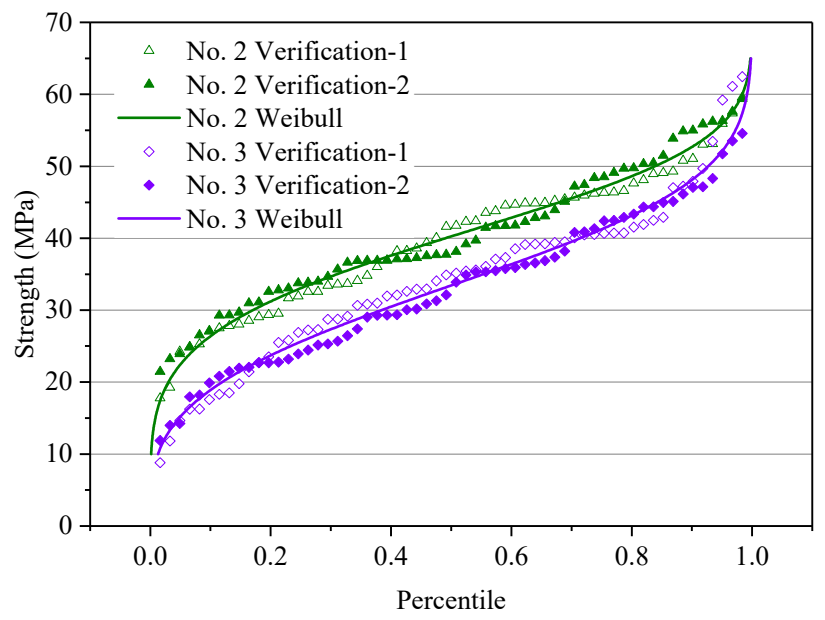

(a)

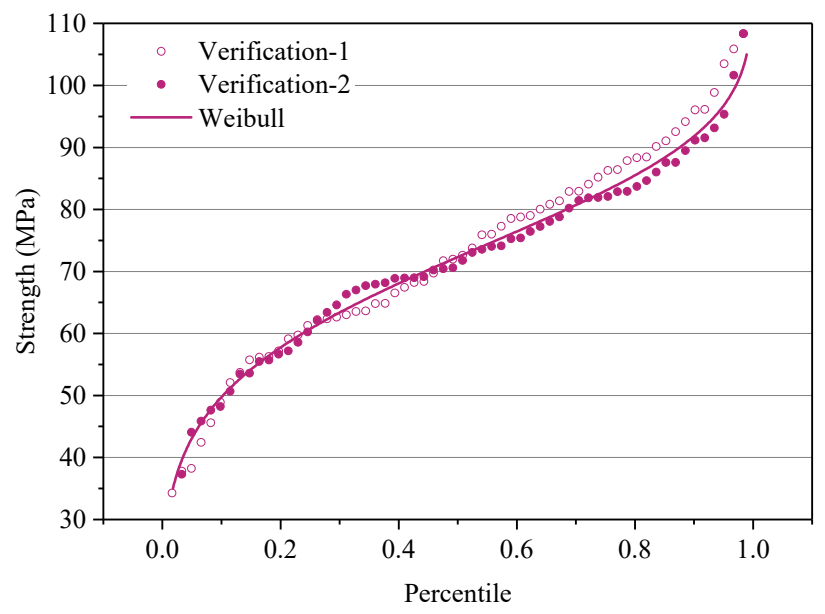

(b)

Figure 4. Verification of the calibrated 2-P Weibull distribution model. (a) Dimension lumber, (b) Small clear specimen. 
Table 3. Coefficient of determination $R^{2}$ of the verification.

\begin{tabular}{ccccccc}
\hline & \multicolumn{2}{c}{ No. 2 } & \multicolumn{2}{c}{ No. 3 } & \multicolumn{2}{c}{ Clear Wood } \\
\cline { 2 - 6 } & Group 1 & Group 2 & Group 1 & Group 2 & Group 1 & Group 2 \\
\hline$R^{2}$ & 0.985 & 0.977 & 0.971 & 0.988 & 0.981 & 0.989 \\
\hline
\end{tabular}

\subsection{Long-Term Test Results}

The applied stress and specimen failure results in long-term test are listed in Table 4, and the short-term and long-term strength from the tests are shown in Figure 5. Table 4 shows that the numbers of the BOL's in the test are indeed very close to the expectations introduced in Section 2.4. This also proves the effectiveness of the sample matching.

Table 4. Applied stress and specimen failure result in long-term tests.

\begin{tabular}{ccccccc}
\hline Specimen & Percentile & Applied Stress (MPa) & BOL & Failure & Survival & Total \\
\hline \multirow{2}{*}{ No. 2 } & 15th & 29.07 & 10 & 27 & 23 & 60 \\
& 25th & 33.05 & 15 & 10 & 39 & 60 \\
\hline \multirow{2}{*}{ No. 3 } & 15th & 21.54 & 16 & 30 & 30 & 60 \\
& 25th & 25.61 & 11 & 33 & 14 & 60 \\
\hline \multirow{2}{*}{ Small clear } & 15th & 54.21 & 15 & 43 & 60 \\
& 25th & 60.73 & & & 60 \\
\hline
\end{tabular}

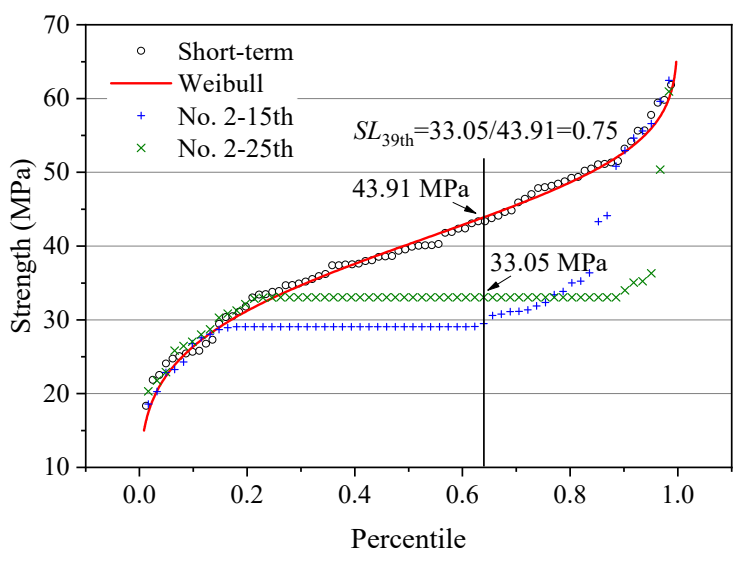

(a)

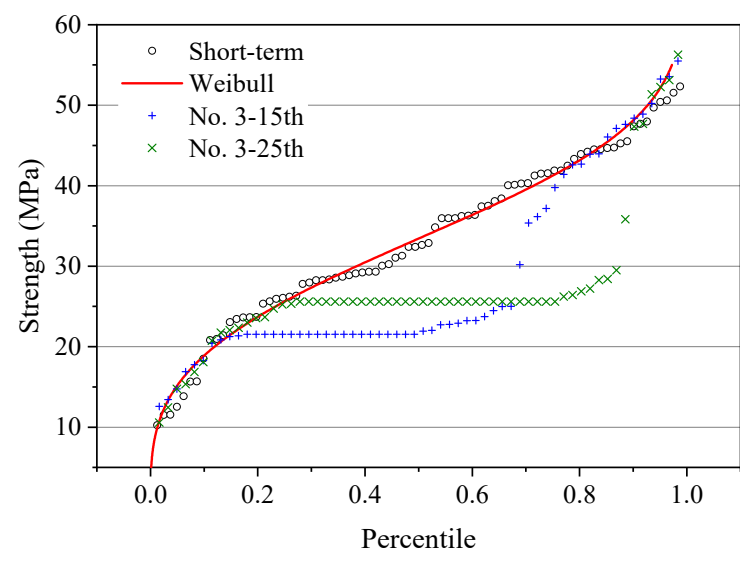

(b)

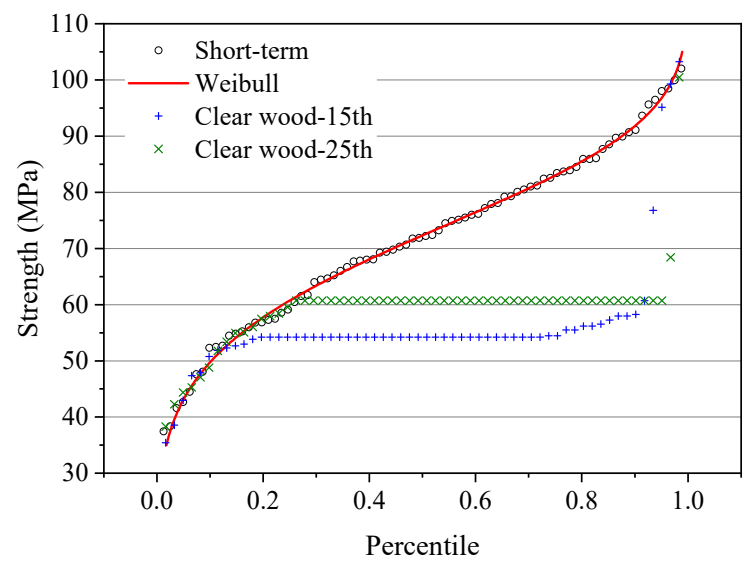

(c)

Figure 5. Short-term and long-term strength from the tests. (a) Grade No. 2 dimension lumber, (b) Grade No. 3 dimension lumber, (c) Small clear specimen. 
Determination of the DOL of a failed specimen is illustrated in Figure 5a for Grade No. 2 dimension lumber under stress level equaling to 25 th percentile of the short-term strength. Following the sample matching technique, the short-term strength of the specimens in the long-term test was the same as that of the specimens for short-term test. Taking the 24th failed specimen in the constant loading stage of long-term test as an example, the strength sequence number is 39 , taking the number of BOL. The short-term strength percentile of this failed specimen is $0.64(=39 / 61)$, corresponding to a strength value of $43.91 \mathrm{MPa}$ by Equation (1). Therefore, the stress ratio representing the DOL of this failed specimen is $0.75(=33.05 / 43.91)$.

DOL of the failed specimens under constant load is shown in Figure 6a-c, together with the Madison Curve, Wood's curve and the results from related studies. DOL results averaged between the two curves with respect to the two applied stress levels are shown in Figure 6d. This is meant to reflect the difference in DOL, if any, between the two lumber grades and that between structural timber and the clear wood.

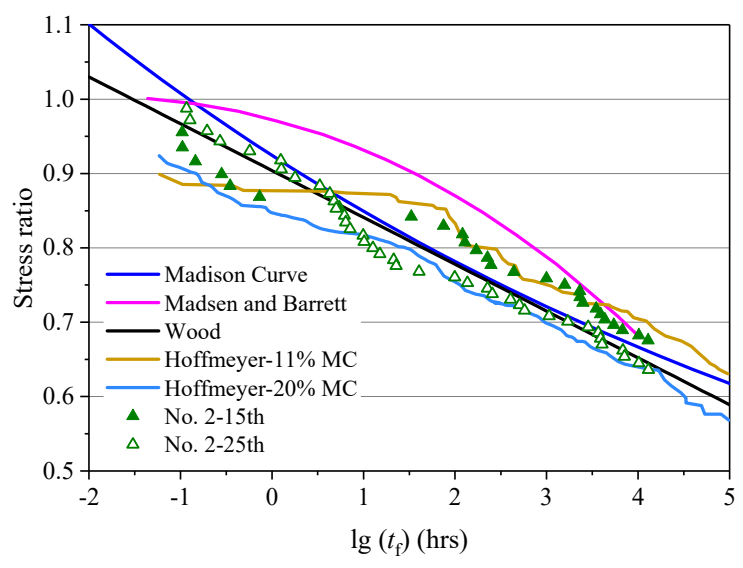

(a)

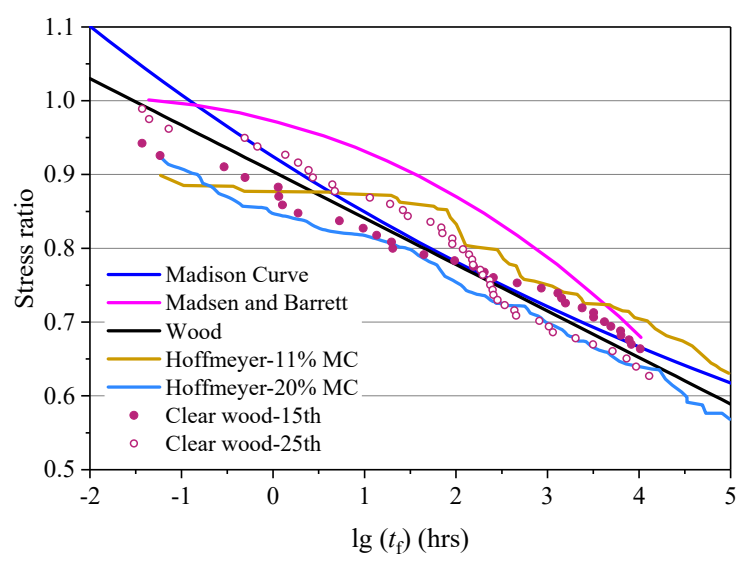

(c)

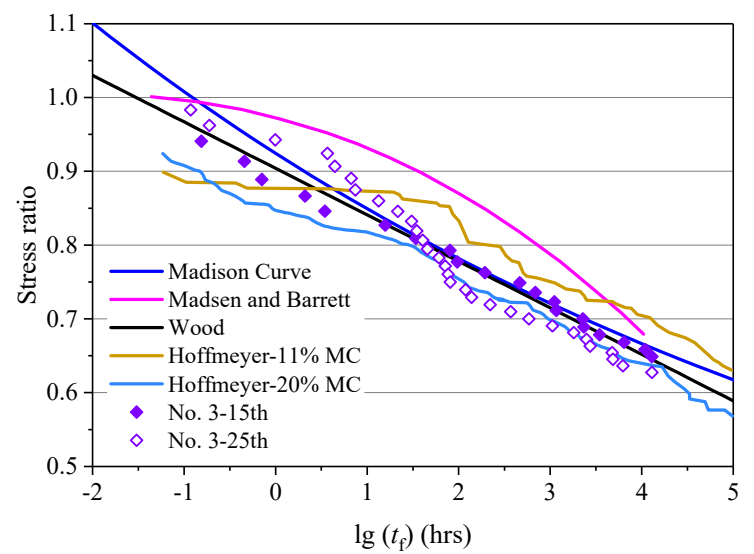

(b)

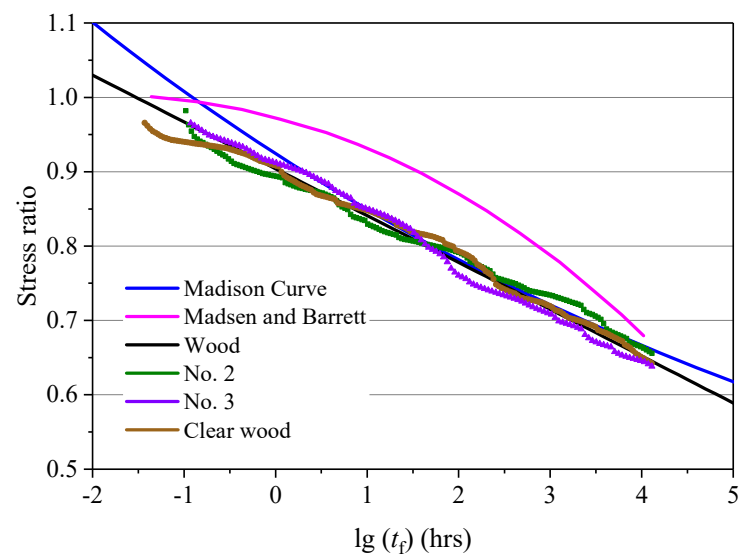

(d)

Figure 6. DOL obtained from the test. (a) Grade No. 2 dimension lumber, (b) Grade No. 3 dimension lumber, (c) Small clear specimen, (d) Averaged DOL between the two stress levels.

Moreover, the strength loss of the survival specimens is reflected by the strength reduction coefficient, which is defined as the ratio of the residual strength to the short-term strength estimated with the sample matching technique, as shown in Figures 7a, 8a and 9a. It can be seen that, the reduction coefficient of some specimens falls below 1.0, indicating that strength loss has happened to these specimens. The mean strength reduction coefficient of these specimens is 0.67 for Grade No. 2 dimension lumber, 0.64 for Grade No. 3 dimension lumber and 0.66 for the small clear specimens. These values are all close to the 
Madison Curve prediction of 0.66 in 18 months. This means that DOL of wood can be evaluated from the failed specimens in long-term loading, it can also be evaluated from testing of the residual strength of the survival specimens.

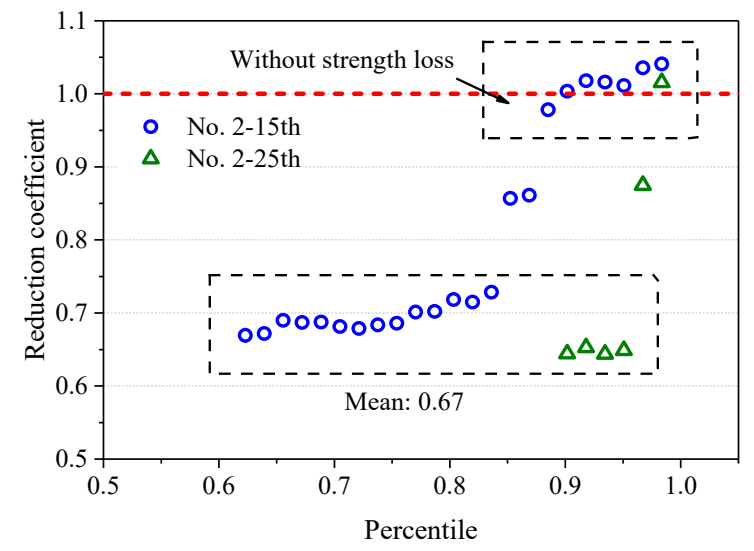

(a)

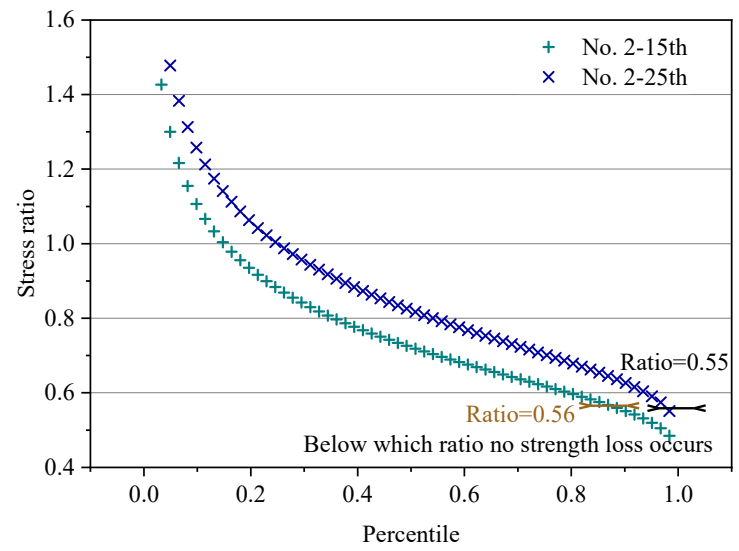

(b)

Figure 7. Test results of Grade No. 2 dimension lumber. (a) Strength reduction coefficient of the survivals, (b) Stress ratios of all specimens.

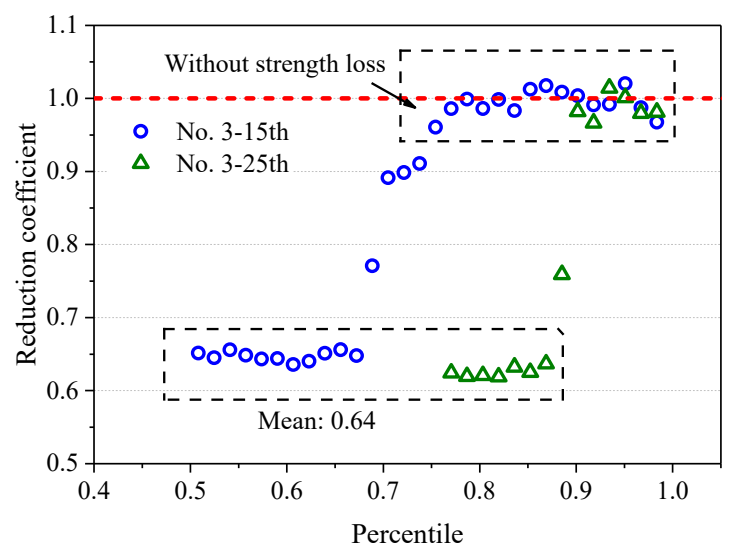

(a)

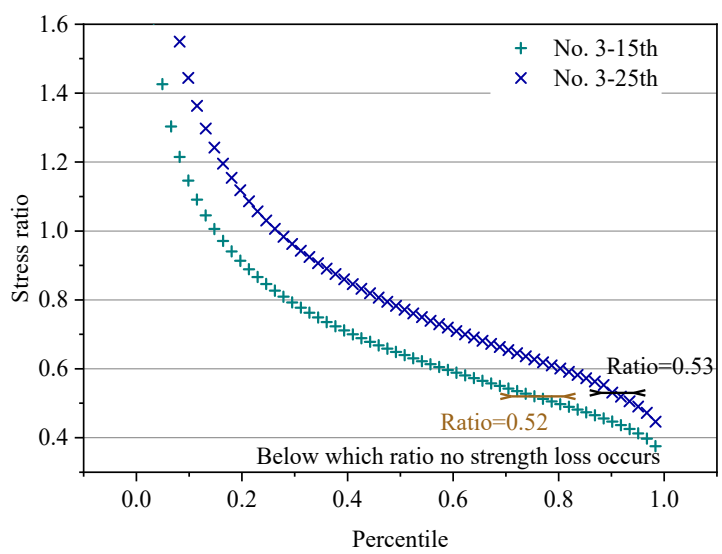

(b)

Figure 8. Test results of Grade No. 3 dimension lumber. (a) Strength reduction coefficient of the survivals, (b) Stress ratios of all specimens.

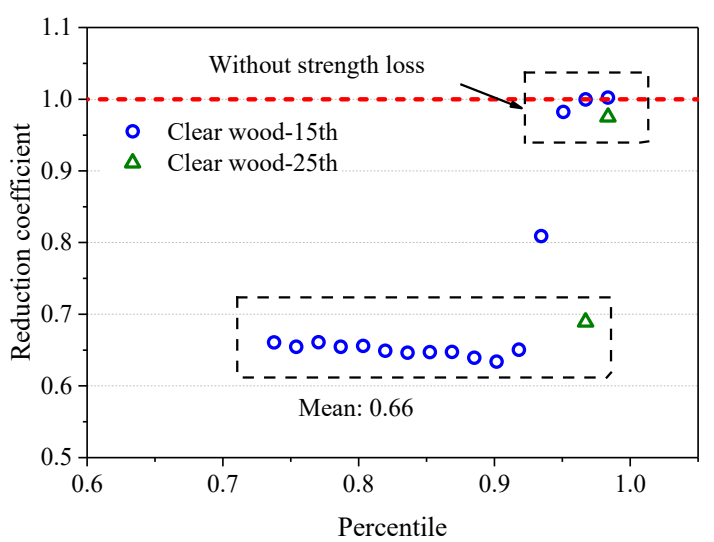

(a)

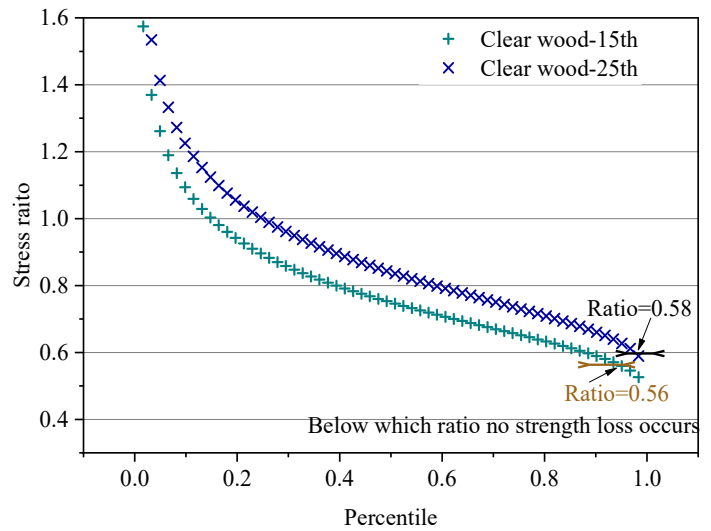

(b)

Figure 9. Test results of clear wood. (a) Strength reduction coefficient of the survivals, (b) Stress ratios of all specimens. 
Furthermore, as shown in Figures 7a, 8a and 9a, with increasing strength percentile of specimens, the reduction coefficient of the survival specimens begins to approach 1.0, indicating that the long-term strength of these specimens of high strength percentile is close to their short-term strength and strength loss has not happened to these specimens. An explanation to this can be that, Figures $7 \mathrm{~b}, 8 \mathrm{~b}$ and $9 \mathrm{~b}$ show the stress ratio of all specimens in the long-term test based on the sample matching, as the strength percentile of specimen increases, the stress ratio decreases. The strength loss seems not to occur when the stress ratio of specimens falls below a certain value, i.e., threshold stress ratio, which is 0.56 for Grade No. 2 dimension lumber, 0.53 for Grade No. 3 dimension lumber and 0.57 for the small clear specimens. This indicates that there is a threshold stress ratio of about 0.55 (mean of the above-listed values) only beyond which wood begins to suffer strength loss, i.e., DOL. Also, this verifies the threshold stress concept in some damage accumulation models [24].

The cumulative distributions of the reduction coefficient of MOE, i.e., the ratio of long-term to short-term MOE, are shown in Figure 10. The MOE of almost all the survival specimens is decreased, with a smallest reduction coefficient being 0.81 . The mean reduction coefficient of MOE for Grade No. 2, No. 3 dimension lumber and the clear wood is $0.92,0.90$ and 0.93 , respectively, which are all less than the mean reduction coefficient of 0.66 of the residual strength relative to the short-term strength as discussed in Section 3.2.

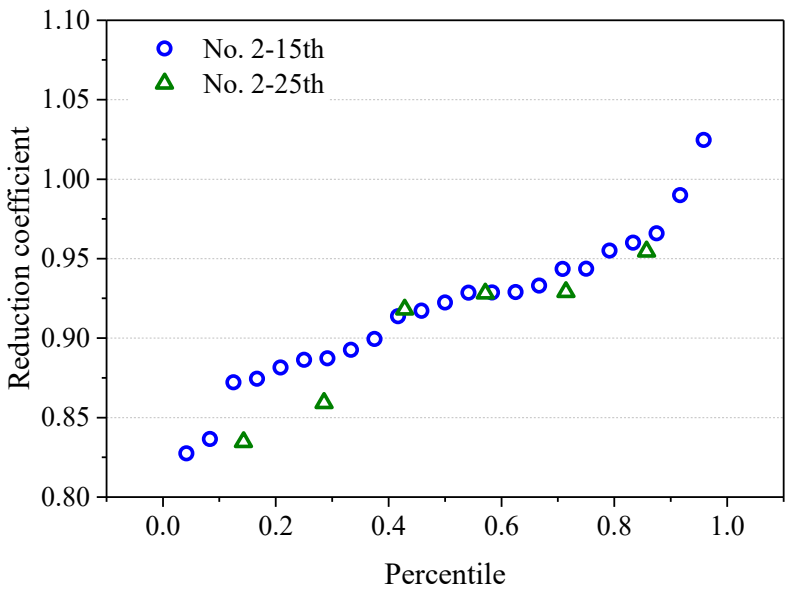

(a)

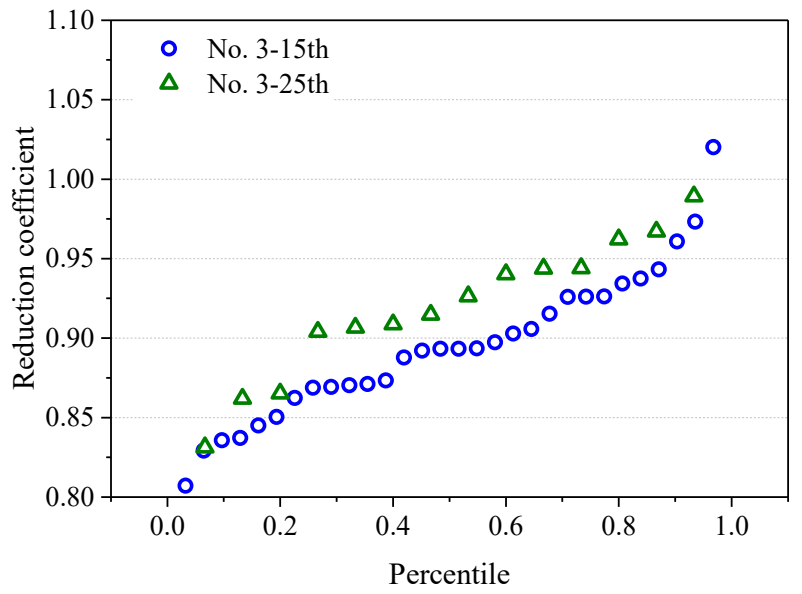

(b)

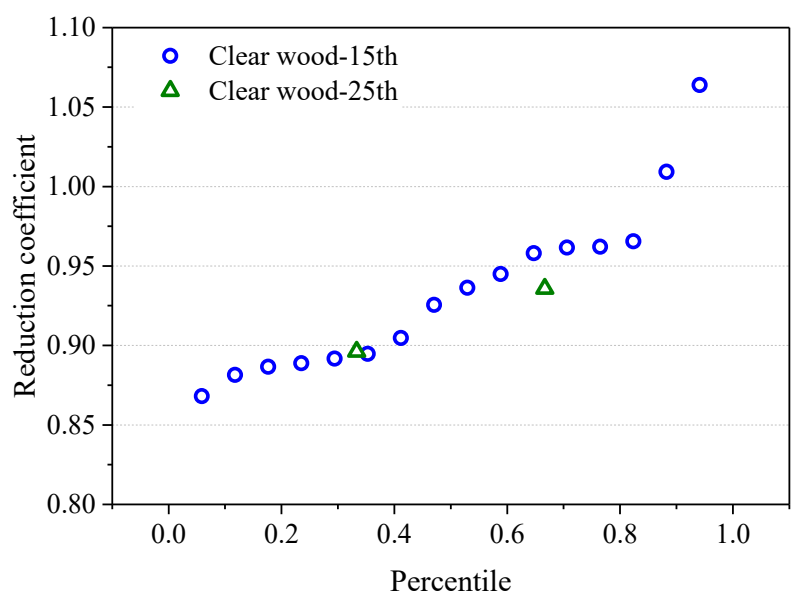

(c)

Figure 10. Cumulative distribution of reduction coefficient of MOE. (a) Grade No. 2 dimension lumber, (b) Grade No. 3 dimension lumber, (c) Small clear specimen. 


\section{Discussion}

As for the strength loss shown in Figure 6a-c. For dimension lumber, data points from this study almost all lie lower (more severe) than the results by Madsen and Barrett, and they are close to Wood's curve and the Madison Curve. The difference between the results of this study and the Madison Curve is relatively larger in the front portion, indicating that in obtaining the Madison Curve by combining Wood's results with the impact test by Elmendorf might give a less severe estimation of DOL. Comparing results of this study with the results of Hoffmeyer and Sørensen's [14], the latter is more severe in the front portion of the curve, and then the data points of this study almost all go between the results of timber with MC of $11 \%$ and the results of timber with MC of $20 \%$ by Hoffmeyer and Sørensen. Test results of small clear specimens show the same trend as dimension lumber, they tend to be closer to Wood's curve, though with some fluctuations. It is worth pointing out that, none of the DOL curves in this study presents a convex shape as Madsen and Barrett's test results did, whilst another study regarding the DOL of wood in tension perpendicular to grain indeed presented a trend similar to Madsen and Barrett's [15].

The Analysis of Variance (ANOVA) was conducted on the strength loss of Grade No. 2, Grade No. 3 dimension lumber and the clear wood as shown in Figure 6d, resulting in $p$-Value $=0.995>0.05$. This indicates that there is virtually no difference among the three averaged curves of Grade No. 2, Grade No. 3 dimension lumber and the clear wood. This indicates that the lumber grade or quality considered in this study does not affect the DOL, and there is virtually no difference in DOL between structural timber and the clear wood, either. If considering the clear wood as the timber of quality higher than Grade No. 2 dimension lumber, this justifies further the point of view that timber quality does not affect the DOL. Since the main factors that affect the strength of wood are the natural defects, which determine the quality of wood, test evidence from this study that the quality does not affect DOL of wood in fact reveals that defects of wood do not affect the DOL. An explanation to this can be that, DOL is due to the viscosity of wood that would be largely the same even if the wood is with different degrees of defects.

Moreover, the three averaged curves are more in agreement with Wood's curve than with the Madison Curve. Employing the form of the equation of Wood's curve, linear fitting of the relationship between the logarithmic time of failure and the stress ratio using all the data points that form the three averaged curves in Figure $6 \mathrm{~d}$ from this study gives

$$
S L=89.90-5.96 \lg \left(t_{\mathrm{f}}\right)
$$

where $S L$ is the stress ratio representing the DOL (\%); $t_{\mathrm{f}}$ is the time to failure (hours). The predicted stress ratio at 1.5 years using Equation (2) is 0.65 , which is very close to or even exactly the same as the mean strength reduction coefficient of 0.66 of all survival specimens, Wood's curve prediction of 0.65 and the Madison Curve prediction of 0.66.

As for the reduction coefficient of MOE shown in Figure 10, the test results indicates that load duration does have a decreasing effect on MOE of wood, although this effect is less severe than that poses on strength of wood. The same conclusion was also drawn from the DOL study of wood in tension perpendicular to grain [15]. It seems that DOL of strength can now be explained as that the wood is damaged under sustained load, so the strength of wood is decreased. The MOE of the damaged wood must also be decreased, though it is to less severe degree. It can be seen that neither the assumption that DOL of MOE is the same as the strength of wood nor the assumption that MOE is without DOL is consistent with the findings of this study. Further investigation of the DOL of MOE is needed.

\section{Conclusions}

Short-term and long-term bending tests of Spruce-Pine-Fir dimension lumber and the clear wood were conducted, DOL of structural timber of different quality and clear wood was experimentally investigated under the same environmental conditions and test methods. Conclusions can be drawn as follows: 
(1) The sample matching technique used to evaluate the short-term strength of structural timber and the clear wood yields reliable results.

(2) So far as the test evidence in this study reveals, in contrast to Madsen and Barrett's findings, there is virtually no difference in DOL between strength grades or quality of structural timber and no difference between structural timber and the clear wood. Also evidenced by the test is that DOL of both structural timber and the clear wood is more in agreement with Wood's curve than the Madison Curve.

(3) Ramp loading of the specimens that survived the long-term loading showed that there is a threshold stress ratio of about 0.55 . Only when wood is loaded beyond the threshold stress level does it begin to experience strength loss.

(4) Based on the threshold stress concept, DOL of wood can be obtained from failures during the long-term loading, it can also be obtained by ramp loading test of the survival specimens.

(5) Duration of load also reduces MOE of wood, though the decrease of MOE is of less degree than that of the strength.

Author Contributions: Q.W., Original drafting, review and editing; L.H., Data curation; E.Z., Conceptualization and validation; S.N., Investigation; H.W., Methodology. All authors have read and agreed to the published version of the manuscript.

Funding: The authors acknowledge with gratitude the financial support of this study from National Natural Science Foundation of China (project designation 51778187), and General Program of Natural Science Foundation of Shandong Province (project designation ZR2019MEE047).

Institutional Review Board Statement: Not applicable.

Informed Consent Statement: Not applicable.

Data Availability Statement: All the data is contained within this article.

Acknowledgments: The authors acknowledge the advice and help offered by Jinglong Pan in Harbin Institute of Technology.

Conflicts of Interest: The authors declare no conflict in the complete research.

\section{References}

1. Buffon, G.L.L. Experiences sur la Force du Bois. Paris L'Acad. R. desSci. Hist. Mem. 1740, 327, $453-467$.

2. Thurston, R.H. On the effect of prolonged stress upon the strength and elasticity of pine timber. J. Franklin Inst. 1881, 112, 161-169. [CrossRef]

3. Wood, L.W. Behavior of wood under continued loading. Eng. News-Rec. 1947, 139, 108-111.

4. Wood, L.W. Relation of Strength of Wood to Duration of Load; Report No. 1916; Forest Products Laboratory: Madison, WI, USA, 1951.

5. Liska, J.A. Effect of Rapid Loading on the Compressive and Flexural Strength of Wood; Report No. 1767; Forest Products Laboratory: Madison, WI, USA, 1950.

6. $\quad$ Elmendorf, A. Stresses in impact. J. Franklin Inst. 1916, 182, 771-790. [CrossRef]

7. Madsen, B. Structural Behaviour of Timber; Timber Engineering Ltd.: Vancouver, BC, Canada, 1992.

8. Madsen, B.; Barrett, J.D. Time-strength relationship for lumber. In Structural Research Series; Report No. 13; UBC: Vancouver, BC, Canada, 1976.

9. Karacabeyli, E.; Soltis, L. State of the art report on duration of load research for lumber in North America. In Proceedings of the International Timber Engineering Conference, London, UK, 2-5 September 1991; Volume 4, pp. 141-155.

10. Hoffmeyer, P. Strength under long-term loading. In Timber Engineering; Thelandersson, S., Larsen, H.J., Eds.; John Wiley \& Sons, Ltd.: Chichester, UK, 2003.

11. Foschi, R.O.; Barrett, J.D. Load duration effects in Western hemlock lumber. J. Struct. Eng. 1982, 108, 1494-1510. [CrossRef]

12. Gerhards, C.C. Bending creep and load duration of Douglas-fir 2 by 4 s under constant load for up to 12-plus years. Wood Fiber Sci. 2000, 32, 489-501. [CrossRef]

13. Gerhards, C.C. Effect of grade on load duration of Douglas-fir lumber in bending. Wood Fiber Sci. 1988, 20, $146-161$.

14. Hoffmeyer, P.; Sørensen, J.D. Duration of load revisited. Wood Sci. Technol. 2007, 41, 687-711. [CrossRef]

15. Wu, Q.Y.; Niu, S.; Wang, H.J.; Jin, Y.B.; Zhu, E.C. An investigation of the DOL effect of wood in tension perpendicular to grain. Constr. Build. Mater. 2020, 256, 119496. [CrossRef]

16. Zhu, E.C.; Huo, L.L.; Niu, S. How stability coefficient agrees and differs between national codes and how it is addressed in code GB 50005. In Proceedings of the World Conference on Timber Engineering 2018, Seoul, Korea, 20-23 August 2018. 
17. Eurocode 5. EN 1995-1-1 Eurocode 5: Design of Timber Structures—Part 1-1: General—Common Rules and Rules for Buildings; European Committee for Standardization: Brussels, Belgium, 2004.

18. ANSI/AWC NDS-2018. National Design Specification for Wood Construction; American Wood Council: Washington, DC, USA, 2018.

19. Norén, B. Results of Pair-Matching of Wood for Long-Term Loading; No. SP 27; International Workshop on Duration of Load in Lumber and Wood Products; Forintek Canada Corporation: Vancouver, BC, Canada, 1986.

20. GB/T 50329-2012. Standard for Test Methods of Timber Structures; Ministry of Housing and Urban-Rural Development of the People's Republic of China: Beijing, China, 2012.

21. GB/T 1936.1-2009. Method of Testing Bending Strength of Wood; Standardization Administration of the People's Republic of China: Beijing, China, 2009.

22. Link, C.L.; Gerhards, C.C.; Murphy, J.F. Statistical Considerations in Duration of Load Research; Res. Pap. FPL487; Department of Agriculture, Forest Service, Forest Products Laboratory: Madison, WI, USA, 1988.

23. EN 408. Timber Structures—Structural Timber and Glued Laminated Timber-Determination of Some Physical and Mechanical Properties; European Committee for Standardization: Brussels, Belgium, 2010.

24. Foschi, R.O.; Yao, Z.C. Another look at three duration of load models. In Proceedings of the 19th CIB/W18 Meeting, Florence, Italy, 1-5 September 1986. 